\title{
PReS-FINAL-2333: Long term efficacy of interleukin-1 receptor antagonist (anakinra) in a multicentric cohort of patients affected by idiopathic recurrent pericarditis
}

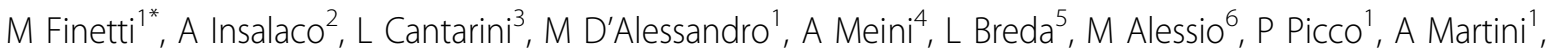 \\ M Gattorno ${ }^{1}$
}

From 20th Pediatric Rheumatology European Society (PReS) Congress

Ljubljana, Slovenia. 25-29 September 2013

\section{Introduction}

Recurrent pericarditis represents an important complication of acute pericarditis. Therapeutic approach during recurrences consists of NSAID (non-steroidal anti-inflammatory drugs) administration. However steroid is often necessary to control disease flares. IL-1 inhibitors efficacy has been anecdotally described as effective in the control of the disease in steroid-dependent and colchicineresistant patients.

\section{Objectives}

To evaluate the long term response to treatment with anakinra (IL-1 receptor antagonist) in a multicenter cohort of patients (pts) affected by idiopathic recurrent pericarditis.

\section{Methods}

Fifteen pts (12 pediatrics, 3 adults; M:F = 11:4) followed by 6 national referral centers were enrolled in the study. The mean age was 22 years (range 8-60 yrs); mean age at onset 16 years ( $5-49 \mathrm{yrs})$, mean age at the beginning of treatment 19 years (6-56 yrs). All pts received an initial dosage of $1-2 \mathrm{mg} / \mathrm{Kg} /$ die. All pts were steroiddependent and 14 of them had received colchicine. Recurrence was documented in patients who presented typical chest pain and 1 or more of the following signs: fever, rubs, electrocardiographic changes, pericardial effusion, increase of acute phase reactants. Outcomes evaluated in our study were i)response to anakinra,

${ }^{1}$ Unit II Pediatrics, G. Gaslini Institute, Genoa, Italy

Full list of author information is available at the end of the article defined as resolution of pericardial symptoms associated to normalization of laboratory-instrumental findings after first administration of the drug; ii)long term remission during IL-1 receptor antagonist regimen defined as absence of relapses during monotherapy; iii)resolution after anakinra discontinuation.

\section{Results}

All pts that received anakinra during active disease (13 pts) presented a dramatic response with a very rapid disappearance of precordial pain, fever, rubs and normalization of acute phase reactants within a few hours from drug administration. Continuous therapy allowed rapid tapering and then discontinuation of steroid, colchicine and NSAID. During continuous daily treatment (mean FU $=12$ months, range 5-17 months), no pt presented a relapse of the disease; 14 pts started tapering and 8 of them experienced a relapse (mean time since tapering start to relapse $=9$ months, range 2-17 months). In all pts disease flare was successfully and quickly controlled by daily full-dose administration of anakinra, without the requirement of any steroid treatment. A total of 10 flares has been observed in these 8 pts. In 5 pts Anakinra was successfully discontinued after 24 months of treatment (range 17-32 months). The mean time of remission since the withdrawn of the drug is now 12 months (range 2-24 months). At the last follow-up all pts were in remission. Three pts are still receiving daily administration of anakinra as monotherapy. In 7 patients anakinra tapering is ongoing. 


\section{Conclusion}

The long term use of anakinra in monotherapy is associated to a persistent control of clinical-laboratoristicinstrumental features of idiopathic recurrent pericarditis. In almost $50 \%$ of the patients reactivation of clinical manifestations during anakinra tapering was observed.

\section{Disclosure of interest}

None declared.

\section{Authors' details}

${ }^{1}$ Unit II Pediatrics, G. Gaslini Institute, Genoa, Italy. ${ }^{2}$ Ospedale Pediatrico Bambin Gesù, Rome, Italy. ${ }^{3}$ Policlinico Le Scotte, Università di Siena, Siena, Italy. ${ }^{4}$ Spedali Civili di Brescia, Brescia, Italy. ${ }^{5}$ Ospedale Policlinico di Chieti, Chieti, Italy. ${ }^{6}$ Università di Napoli Federico II, Naples, Italy.

Published: 5 December 2013

doi:10.1186/1546-0096-11-S2-P323

Cite this article as: Finetti et al:: PReS-FINAL-2333: Long term efficacy of interleukin-1 receptor antagonist (anakinra) in a multicentric cohort of patients affected by idiopathic recurrent pericarditis. Pediatric

Rheumatology 2013 11(Suppl 2):P323.

Submit your next manuscript to BioMed Central and take full advantage of:

- Convenient online submission

- Thorough peer review

- No space constraints or color figure charges

- Immediate publication on acceptance

- Inclusion in PubMed, CAS, Scopus and Google Scholar

- Research which is freely available for redistribution

Submit your manuscript at www.biomedcentral.com/submit 